\title{
Analysis of Tactical Performance of Youth Soccer Players
}

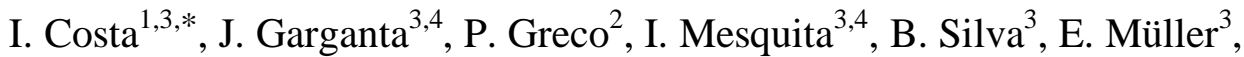 \\ D. Castelão ${ }^{3}$, A. Rebelo ${ }^{3,4}$ and A. Seabra ${ }^{3,4}$ \\ ${ }^{1}$ University Center of Belo Horizonte, UNI-BH, Belo Horizonte, MG-Brazil \\ ${ }^{2}$ Federal University of Minas Gerais, UFMG, Belo Horizonte, MG-Brazil \\ ${ }^{3}$ Faculty of Sport, University of Porto, FADEUP, Porto, Portugal \\ ${ }^{4}$ Centre of Research, Education, Innovation and Intervention in Sport, CIFI D, FADEUP, Porto, Portugal
}

\begin{abstract}
The aim of this study was to analyze tactical performance of youth soccer players concerning different age groups, according to the tactical game principles and action's place and outcome. The sample comprised 106 youth players who performed 2915 defensive and 2662 offensive tactical actions. The normal distribution of the data was verified by the test of Kolmogorov-Smirnov ( $\mathrm{p} \leq 0.05$ ). Analysis of variance (ANOVA) was used to compare the values of the performance indexes, concerning tactical actions. The results show significant statistical differences for all tactical performance indexes $(\mathrm{p} \leq 0.05)$ Also, it confirms that most of youth teams had better performance indexes for the "depth mobility" and "defensive coverage" principles. It is possible to conclude that the lowest offensive performance index concerns to "width and length" principle, for all youth age groups. In addition, the lowest defensive performance index, concerning "concentration", "defensive unity" and "delay" principles, showed a dependence of the age group in order these principles. It is also reasonable to conclude that youth players showed higher difficulties to be efficient in defensive tactical actions in the offensive midfield.
\end{abstract}

Keywords: Soccer, tactical performance, youth teams, game principles.

\section{INTRODUCTION}

The analysis of tactical demands has gained great importance for scientists and coaches, since both are interested in understanding successful game patterns in team sports. While the objective of sport researchers focuses on attaining more knowledge about the training process, coaches attempt to set up training situations, which lead the team to competitive success [1-3].

Researches that deal with tactical performance in soccer have been using Notational Analysis [4] and Observational Methodology procedures [5]. These tools provide information regarding patterns of play that could be a very powerful tool in attempting a better understanding of the sport and helping to formulate a successful game-plan prior to matches.

The aim of this study was to analyse tactical performance of youth soccer players concerning different age groups, according to the tactical game principles, place of action and action outcome.

\section{MATERIAL AND METHODS}

\section{Participants and Sample}

In the present study, 106 players (42 Under-11s, 16 Under-13s, 24 Under-15s and 24 Under-19s) were analyzed.

\footnotetext{
*Address correspondence to this author at the Centro de Estudos em Cognição e Ação (CECA), Escola de Educação Física, Fisioterapia e Terapia Ocupacional da UFMG, Av. Presidente Antônio Carlos, 6627Pampulha, Belo Horizonte - Minas Gerais - Brazil; Cep: 31.310-250; Tel/Fax: 0XX (31) 3499-2325; E-mail: israelteoldocosta@googlemail.com
}

These players performed 2915 defensive and 2662 offensive tactical actions. Data from throw-ins, free kicks and situations where the player didn't move, were not analyzed.

\section{Applied Method}

Players performed a 4 minute small-sided game $(3 v s .3$ with goalkeepers). The "GK3-3GK" test is designed in a field of 36 meters length and 27 meters width. With the exception of the offside rule, all official Soccer rules were applied. The test aimed to evaluate the tactic actions performed by players (with and without the ball) attending on ten fundamental tactical principles of Soccer game. Additionally, the test considered the place of action and the action outcome. Based on this information several indexes of performance were calculated, concerning tactical game principles, place of action and action outcome.

\section{Procedure}

The data for our study was attained in four different clubs with directors' permission. Prior to the test, a brief explanation of the objectives was given to the players. The teams were formed randomly and the players were wearing numbered vests in order to facilitate their identification. A thirtysecond period had been granted to familiarize them with the test and after which the game began.

\section{Materials}

The games were recorded with a digital camera PANASONIC NV - DS35EG. The digital videos were transferred to a laptop via cable and converted into "avi" files. Soft- 
wares Utilius VS and Soccer Analyser were used for data processing.

\section{Statistical Analysis}

Statistical procedures were done using SPSS for Windows ${ }^{\circledR}$, version 17.0. Descriptive analyses (frequency, means and standard-deviation) were carried out to characterize the sample. The normal distribution of the data was verified by the test of Kolmogorov-Smirnov and homogeneity of variances was assured by test of Levene. The analysis of variance (ANOVA) was used to compare the values of the performance indexes, concerning tactical actions and its errors and setting [6]. The Kappa of Cohen coefficient was used to check inter- and intra-observers reliability.

\section{Reliability Analysis}

To determine the reliability of the observation, the testretest method was used to obtain the stability-reliability coefficient. Three observers were trained to review 1032 tactical actions that represent $18.5 \%$ of the sample. This percentage is above the value of reference $(10 \%)$ recommended by the literature [7]. The results reveals an inter-observers agreement coefficient of 0.93 (standard-deviation $=0.02$ ), 0.82 (standard-deviation $=0.02$ ) and 0.85 (standard-deviation $=0.02$ ) and intra-observers agreement coefficient of 0.92 ( standard-deviation $=0.01), 0.87$ (standard-deviation $=0.02$ ) and 0.90 (standard-deviation $=0.02$ ). These values are above the conventional level of acceptance (0.61) [8].

\section{RESULTS AND DISCUSSION}

Table 1 displays age group means and standard-deviation of Tactical Performance Indexes (IPT). It shows that three youth teams had better IPT's for the "Depth Mobility" and "Defensive Coverage" principles. Another team (under-13) had the highest IPT mean for the "Penetration" and "Balance" principles.

The lowest values of IPT were similar for all youth teams for offensive phase, Width and Length", and game's phases "Defensive Phase. Regarding the defensive principles, the lowest values seem to be dependent on age. Analysis of variance shows that all the analyzed values of performance are statistically different $(\mathrm{p}<0.05)$. This result illustrates that tactical performances are different between all age groups and improve with age, except for the Under-11 group.

Table 2 presents the means and standard-deviation of actions, percentage of errors and principles application in defensive and offensive midfield. Regarding game actions performed, it appears that the highest values concerns to the same principles ("Width and Length" and "Defensive Unity") to all age groups, except the value of "Offensive Coverage" that was higher for the Under-11 group.

The principles less performed were "Defensive Coverage" in the defensive phase, and "Offensive Unity", "Depth Mobility" and "Penetration" in the offensive phase. Analysis of variance indicated that all mean values of the actions were statistically significant $(p<0.05)$. These results show that there is an increase in the number of performed actions in game according to the age boost, except for the Under-13 group.

The data relating to the percentage of errors showed that the players from three age groups (Under-11, Under-15 and Under-19) presented a higher mean on the "Offensive Unity" and "Delay" principles. Only the Under-13 group was different, performing more errors on the "Offensive Coverage" and "Defensive Unity" principles. Moreover, it is understandable that players could incur in more errors on the "Defensive Phase" than the "Offensive Phase". Analysis of variance showed that only four values of the principles did not reveal statistical differences $(\mathrm{p}<0.05)$. This result suggests that youth players' errors seem to happen in specific game contexts considering its development stage.

The last variable (Table 2) refers to the "principles application in defensive and offensive midfield", meaning the place where tactical actions had been carried through. Thus, the data related with the offensive principles elapses from the actions performed in the defensive midfield, while the defensive principles elapses from the actions performed in the offensive midfield.

The results also showed that the highest and the lowest values of this variable were related with common principles for the majority of the youth age groups. The highest values concern to the "Width and Length" and "Defensive Unity" principles as well as "Offensive Phase". Lowest values were found in the "Depth Mobility" and "Defensive Coverage" principles as well as in the "Defensive Phase". This result suggests that in general the players reveal more difficulty to perform tactical actions related with game defensive principles.

Analysis of variance indicated that only four principles did not confirm statistical differences $(p<0.05)$ between groups. These results suggest that the players executed more actions of the offensive and defensive principles in the offensive midfield, and it is possible to note higher differences

Table 1. Means and Standard-Deviation of Performance Indexes

\begin{tabular}{|c|c|c|c|c|c|c|c|c|c|c|c|c|c|c|}
\hline & & Penetration & $\begin{array}{l}\text { Offensive } \\
\text { Coverage }\end{array}$ & $\begin{array}{c}\text { Depth } \\
\text { Mobility }\end{array}$ & $\begin{array}{l}\text { Width and } \\
\text { Length }\end{array}$ & $\begin{array}{l}\text { Offensive } \\
\text { Unity }\end{array}$ & $\begin{array}{c}\text { Offensive } \\
\text { Phase }\end{array}$ & Delay & $\begin{array}{l}\text { Defensive } \\
\text { Coverage }\end{array}$ & Balance & $\begin{array}{l}\text { Concen- } \\
\text { tration }\end{array}$ & $\begin{array}{c}\text { Defensive } \\
\text { Unity }\end{array}$ & $\begin{array}{c}\text { Defensive } \\
\text { Phase }\end{array}$ & Game \\
\hline \multirow{4}{*}{ 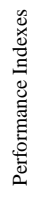 } & Under-11 & $9.86 \pm 4.96$ & $9.54 \pm 2.68$ & $10.94 \pm 3.9$ & $9.07 \pm 2.89$ & $10.11 \pm 5.40$ & $9.76 \pm 2.36$ & $7.09 \pm 2.94$ & $10.80 \pm 7.25$ & $7.01 \pm 3.71$ & $5.89 \pm 2.62$ & $6.54 \pm 1.56$ & $6.57 \pm 1.18$ & $8.27 \pm 1$ \\
\hline & Under-13 & $10.55 \pm 4.45$ & $8.63 \pm 3.59$ & $10.39 \pm 3.58$ & $7.81 \pm 2.53$ & $10.34 \pm 4.17$ & $8.80 \pm 2.02$ & $7.80 \pm 3.42$ & - & $8.28 \pm 4.55$ & $6.31 \pm 3.27$ & $5.93 \pm 1.90$ & $6.93 \pm 0.95$ & $7.78 \pm 1$ \\
\hline & Under-15 & $9.76 \pm 3.75$ & $9.30 \pm 2.08$ & $\frac{11.56 \pm 3.2}{\square}$ & $8.33 \pm 1.48$ & $11.28 \pm 5.34$ & $9.21 \pm 1.48$ & $6.01 \pm 2.93$ & $8.00 \pm 5.56$ & $6.60 \pm 2.67$ & $5.88 \pm 2.23$ & $6.19 \pm 1.55$ & $5.87 \pm 0.96$ & $7.48 \pm 1$ \\
\hline & Under-19 & $11.49 \pm 3.77$ & $9.21 \pm 1.47$ & $15.32 \pm 2.8$ & $8.86 \pm 1.74$ & $10.04 \pm 3.13$ & $9.78 \pm 1.19$ & $5.49 \pm 1.66$ & $8.50 \pm 5.25$ & $7.36 \pm 2.47$ & $5.53 \pm 2.05$ & $6.36 \pm 1.06$ & $6.15 \pm 1.05$ & $7.83 \pm 0$ \\
\hline
\end{tabular}


Table 2. Means and Standard-Deviation of Actions, \%Error and Principles Application in Defensive and Offensive Midfield

\begin{tabular}{|c|c|c|c|c|c|c|c|c|c|c|c|c|c|}
\hline & & Penetration & $\begin{array}{l}\text { Offensive } \\
\text { Coverage }\end{array}$ & $\begin{array}{c}\text { Depth } \\
\text { Mobility }\end{array}$ & $\begin{array}{c}\text { Width and } \\
\text { Length }\end{array}$ & $\begin{array}{c}\text { Offensive } \\
\text { Unity }\end{array}$ & $\begin{array}{c}\text { Offensive } \\
\text { Phase }\end{array}$ & Delay & $\begin{array}{l}\text { Defensive } \\
\text { Coverage }\end{array}$ & Balance & $\begin{array}{c}\text { Concentratio } \\
\mathbf{n}\end{array}$ & $\begin{array}{c}\text { Defensive } \\
\text { Unity }\end{array}$ & $\begin{array}{c}\text { Defensive } \\
\text { Phase }\end{array}$ \\
\hline \multirow{4}{*}{ 泀 } & Under- & $2.69 \pm 1.89$ & $6.80 \pm 3.41$ & $2.64 \pm 2.44$ & $5.76 \pm 4.40$ & $3.61 \pm 2.72$ & $21.52 \pm 8.27$ & $3.80 \pm 2.45$ & $0.38 \pm 0.53$ & $5.85 \pm 3.65$ & $2.04 \pm 2.09$ & $11.54 \pm 4.52$ & $23.64 \pm 9.1$ \\
\hline & Under- & $2.31 \pm 2.52$ & $4.37 \pm 3.18$ & $2.31 \pm 2.02$ & $7.12 \pm 4.55$ & $4.43 \pm 2.73$ & $20.56 \pm 8.10$ & $4.31 \pm 1.92$ & 0.00 & $4.81 \pm 3.14$ & $2.75 \pm 2.51$ & $12.12 \pm 6.95$ & $24.00 \pm 9.4$ \\
\hline & Under- & $2.62 \pm 1.92$ & $8.75 \pm 3.24$ & $3.58 \pm 2.50$ & $9.62 \pm 5.70$ & $2.62 \pm 2.58$ & $27.20 \pm 5.47$ & $3.83 \pm 1.92$ & $0.45 \pm 0.65$ & $7.58 \pm 3.02$ & $4.79 \pm 2.90$ & $12.60 \pm 63.69$ & $29.33 \pm 6.8$ \\
\hline & Under- & $3.62 \pm 1.49$ & $8.45 \pm 4.24$ & $2.41 \pm 1.76$ & $12.91 \pm 5.33$ & $4.91 \pm 2.91$ & $32.33 \pm 7.25$ & $3.87 \pm 2.11$ & $0.16 \pm 0.38$ & $8.25 \pm 3.98$ & $5.00 \pm 3.48$ & $17.45 \pm 4.05$ & $34.75 \pm 8.6$ \\
\hline \multirow{4}{*}{$\begin{array}{l}\text { 䔂 } \\
\text { s。 }\end{array}$} & Under- & $15.92 \pm 9.08$ & $8.08 \pm 12.5$ & $12.78 \pm 22.93$ & $7.54 \pm 19.06$ & $24.54 \pm 33.9$ & $18.98 \pm 19.86$ & $61.10 \pm 27.1$ & $21.42 \pm 40.5$ & $49.93 \pm 29.7$ & $33.42 \pm 37.71$ & $36.41 \pm 24.04$ & $82.64 \pm 67$. \\
\hline & Under- & $8.65 \pm 18.66 *$ & $11.27 \pm 16$. & $11.04 \pm 18.15$ & $7.03 \pm 10.62$ & $9.41 \pm 15.52$ & $9.46 \pm 7.90$ & $41.23 \pm 13.1$ & - & $37.29 \pm 32.2$ & $28.24 \pm 36.68$ & $42.17 \pm 33.78$ & $36.39 \pm 16$. \\
\hline & Under- & $11.89 \pm 24.52$ & $4.77 \pm 8.74$ & $3.98 \pm 14.62 *$ & $13.86 \pm 18.0$ & $16.19 \pm 27.5$ & $10.30 \pm 6.27$ & $59.59 \pm 30.9$ & $20.00 \pm 41.4$ & $46.72 \pm 18.0$ & $22.34 \pm 22.31$ & $28.26 \pm 21.01$ & $35.87 \pm 12$. \\
\hline & Under- & $6.28 \pm 12.65$ & $8.78 \pm 9.24$ & $2.08 \pm 10.20 *$ & $9.18 \pm 12.60$ & $20.14 \pm 28.5$ & $25.45 \pm 23.38$ & $43.60 \pm 28.0$ & 0.00 & $29.72 \pm 12.9$ & $19.74 \pm 31.15$ & $27.02 \pm 22.05$ & $82.01 \pm 75$. \\
\hline \multirow{4}{*}{ 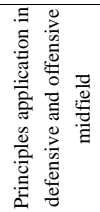 } & Under- & $0.90 \pm 0.84$ & $3.97 \pm 2.16$ & $0.47 \pm 0.74$ & $3.19 \pm 2.08$ & $1.35 \pm 1.37$ & $9.90 \pm 2.98$ & $1.14 \pm 1.07$ & $0.04 \pm 0.21$ & $1.66 \pm 1.52$ & $0.66 \pm 0.78$ & $4.07 \pm 2.36$ & $7.59 \pm 3.29$ \\
\hline & Under- & $0.87 \pm 1.02$ & $2.87 \pm 2.65$ & $0.31 \pm 0.60 *$ & $4.87 \pm 4.04$ & $1.43 \pm 1.15$ & $10.37 \pm 5.07$ & $2.18 \pm 1.72$ & - & $1.93 \pm 1.80$ & $1.06 \pm 0.99$ & $4.50 \pm 2.09$ & $9.68 \pm 4.62$ \\
\hline & Under- & $0.91 \pm 1.28$ & $5.29 \pm 2.92$ & $0.87 \pm 1.48$ & $6.70 \pm 3.93$ & $1.29 \pm 1.60$ & $15.08 \pm 3.90$ & $2.16 \pm 1.63$ & $0.25 \pm 0.44$ & $3.50 \pm 2.46$ & $2.75 \pm 2.21$ & $6.12 \pm 2.96$ & $14.79 \pm 4.9$ \\
\hline & Under- & $1.50 \pm 1.02$ & $5.79 \pm 3.95$ & $0.04 \pm 0.20 *$ & $9.87 \pm 4.63$ & $2.50 \pm 2.10$ & $19.70 \pm 7.30$ & $1.75 \pm 1.70$ & $0.08 \pm 0.28 *$ & $3.33 \pm 3.26$ & $3.04 \pm 2.92$ & $6.70 \pm 2.97$ & $14.91 \pm 8.0$ \\
\hline
\end{tabular}

* Don't have statistical differences (p<0.05) \% ERROR: Under-13: penetration (0.121); Under-15: depth mobility (0.205) and balance (0.082); Under-19: depth mobility (0.328). PRINCIPLES APPLICATION IN DEFENSIVE AND OFFENSIVE MIDFIELD: Under-11: offensive coverage (0.160); Under-13: depth mobility (0.055); Under-19: depth mobility (0.328) and defensive coverage (0.162).

to the older age groups. Probably, it happens because older players possess finer game knowledge and more consistences in their performance.

Therefore, it is possible to conclude that the lowest offensive IPT was in the "Width and Length" principle for all youth age groups. In addition the lowest defensive IPT, concerning "Concentration", "Defensive Unity" and "Delay" principles, showed a dependence of the age group. It is also reasonable to conclude that youth players showed higher difficulties to be efficient in defensive tactical actions in the offensive midfield. This statement is supported by the data of index performance and number of tactical actions. Despite exhibiting more actions, these principles showed a low performance index.

\section{ACKNOWLEDGEMENT}

Supported by the Programme AlBan, the European Union Programme of High Level Scholarships for Latin America, scholarship n E07D400279BR".

\section{REFERENCES}

[1] Gréhaigne JF, Mahut B, Fernandez A. Qualitative observation tools to analyse soccer. Int J Perform Anal Sport 2001; 1(1): 5261.

[2] Garganta J. Modelação táctica do jogo de futebol - estudo da organização da fase ofensiva em equipas de alto rendimento. [Tese de Doutoramento]. Porto: Universidade do Porto 1997.

[3] Garganta J. Analisar o jogo nos jogos desportivos colectivos - uma preocupação comum ao treinador e ao investigador. Horizonte 1998; 14(83): 7-14.

[4] Hughes C, Franks I. Notational analysis of sport. London: E. \& F.N Spon 1997.

[5] Anguera M, Blanco A, Losada J, Hernández A. La metodología observacional en el deporte: Conceptos básicos. Lecturas: EF y Deportes. Rev Digit 2000; 5 (24). Available at: http//: www. efdeportes.com

[6] Pestana MH, Gageiro JN. Análise de dados para ciências sociais: a complementaridade do SPSS. $3^{\mathrm{a}}$ ed. Lisboa: Lisboa Edições Sílabo 2003.

[7] Tabachnick B, Fidell L. Using multivariate statistics. New York: Harper \& Row Publishers 1989.

[8] Landis JR, Koch GC. The measurement of observer agreement for categorical data. Biometrics 1977; 33: 1089-91.

(C) Costa et al.; Licensee Bentham Open.

This is an open access article licensed under the terms of the Creative Commons Attribution Non-Commercial License (http://creativecommons.org/licenses/by-nc/3.0/) which permits unrestricted, non-commercial use, distribution and reproduction in any medium, provided the work is properly cited. 